\title{
PATRONES DE MOMIFICACIÓN CHINCHORRO EN LAS COLECCIONES UHLE Y NIELSEN
}

\author{
CHINCHORRO MUMMIFICATION PATTERNS IN THE UHLE \\ AND NIELSEN COLLECTIONS
}

\author{
Agustín Llagostera M.*
}

\begin{abstract}
Se analizan dos colecciones de cuerpos humanos momificados procedentes del norte de Chile, asignados al Complejo Chinchorro. Una de ellas fue recolectada por el arqueólogo alemán Max Uhle en la costa de Arica y, la otra, por el aficionado danés Ancker Nielsen en las proximidades de Iquique; ambas, durante las primeras décadas del siglo XX. Se describe y reconstruye gráficamente, con la mayor rigurosidad posible, dentro de lo que ha sido factible rescatar los ejemplares de estas colecciones. Se distinguen dos patrones de momificación, de acuerdo al material utilizado para rellenar los cuerpos, sea éste totora o material arcilloso. Destaca el primer tipo por tratarse de una sofisticada modalidad, no descrita para otras colecciones, la que además presenta casos de reposición de piel en vendajes y luego embarrilamiento total de tronco y/o extremidades, con lienza ${ }^{1}$. Para la colección Uhle se dispone de una fecha radiocarbónica de $3690 \pm 60$ a.p., con lo que estas colecciones y sus patrones de taxidermia funeraria se adscribirían como manifestaciones tardías dentro del Complejo Chinchorro.

Palabras claves: Complejo Chinchorro, arcaico costero norte de Chile, momificación compleja, arqueología de Arica e Iquique, Max Uhle, Ancker Nielsen.
\end{abstract}

Two collections of mummified human bodies ascribed to the Chinchorro Complex from Chile were analyzed. One collection was produced by the German archaeologist Max Uhle who excavated along the coast of Arica. The other was collected by the Danish amateur archaeologist Ancker Nielsen in the Iquique area. Both collections were assembled during the first decades of the $20^{\text {th }}$ century. The author graphically described and reconstructed the information about the mummies as rigorously as possible within the limits of what was possible to discover. Two mummification patterns were identified based on the materials used for filling the bodies, either reeds or clay. The first pattern, has not been previously described and stands out due to its complexity. In addition, in this type, the skin was repositioned as bandages and fine cords were used for wrapping the trunk and/or extremities. One mummy from the Uhle collection was radiocarbon dated to $3690+60$ B.P. Consequently, the Uhle collection and its funerary taxidermy patterns could be ascribed to late manifestations within the Chinchorro Complex.

Key words: Chinchorro complex, coastal archaic of northern Chile, complex mummification, Arica and Iquique archaeology, Max Uhle, Ancker Nielsen.

En el marco del proyecto "El hombre arcaico costero: su biodiversidad y su bioadaptación" (Fondecyt 1960169) se planteó la importancia de documentar las colecciones de momias Chinchorro excavadas por Max Uhle y Ancker Nielsen, para insertarlas comparativamente dentro de lo que, hasta el momento, se había descrito y definido para dicha tradición funeraria.

Max Uhle (1917) diferenció vestigios arqueológicos de gente que no conocía la cerámica ni la agricultura, que dependía básicamente de los recursos marinos, y que sometía a sus muertos a un proceso de momificación artificial. A estos grupos denominó "Aborígenes de Arica", nombre que más tarde se sugirió cambiar por Quiani, Cultura Chinchorro, Complejo Chinchorro, Tradición Chinchorro y Fase Chinchorro.
El mencionado estudioso señaló que se pueden distinguir tres clases de momias: (1) momias de tipo sencillo, (2) momias de preparación complicada y (3) momias revestidas en todo el cuerpo con una capa de barro, de un centímetro de espesor. Dice que la primera podría ser tomada como el tipo original; la segunda, como un desarrollo de la primera, producido por el contacto con las civilizaciones peruanas, mientras que la tercera se podría considerar un retroceso hacia los procedimientos sencillos.

La técnica de momificación complicada se habría obtenido de acuerdo al siguiente procedimiento: (a) abertura del vientre y destripamiento completo; (b) disecación de la caverna del cuerpo con fuego y su relleno con otras sustancias menos alterables; además, introducción de palos en el tron-

\footnotetext{
* Instituto de Investigaciones Arqueológicas y Museo, Universidad Católica del Norte, San Pedro de Atacama, Chile.
} 
co y extremidades para enderezar y entiesar el cadáver; por último, cierre y costura del tegumento natural; (c) reconstrucción del exterior del muerto, abultando el tronco y las extremidades con totora. La cara era tapada frecuentemente con una máscara de barro pintada de diferentes maneras. Era muy común agregar una cabellera postiza a las momias de las criaturas (Uhle 1922:65-66).

Décadas después, el análisis del material aportado por el sitio Morro 1, también de Arica, permitió a los arqueólogos perfeccionar la clasificación propuesta por Uhle (Allison et al. 1984) y, más tarde, uno de ellos (Arriaza 1995), involucrando el universo de momias mencionadas en la literatura, pudo complementar y perfeccionar la clasificación:

1) Momias de tratamiento simple: desecación natural de los cuerpos por acción del medio ambiente; extendidas, envueltas con esteras de totora y pieles de camélidos; apoyadas sobre sus espaldas $\mathrm{y}$ algunas con las piernas levemente flectadas.

2) Momias de tratamiento complejo: cuerpos con tratamiento interno, entre las que se distinguen los siguientes subtipos y variedades:

a) Momias Negras: pintadas externamente con una capa de manganeso. Fueron las más complejas de todas. Los cuerpos prácticamente eran reconstruidos; la mayoría de los tejidos blandos eran removidos y el esqueleto reforzado. La cara, cuello, tronco, extremidades y genitales fueron modelados con pasta blanca y luego, completamente pintadas de negro. El tratamiento que produjeron las momias negras no fue igual en todos los casos. Estas momias han sido reportadas para cinco sitios entre Arica y Camarones.

b) Momias Rojas: los cuerpos no fueron desarticulados con la misma intensidad que en las momias negras; en la mayoría de los casos, la piel no fue completamente removida; los huesos de los brazos y piernas no fueron raspados y, aparentemente, el cuerpo no fue completamente desmembrado. El cuerpo fue rellenado con una mezcla de materiales: pasta blanca o negra, lana de camélidos, plumas, pasto, pieles de animales y de aves, tierra. El cuerpo fue modelado y recubierto con pintura roja (óxido de hierro). La cara fue dejada en negro, pero otros colores como negro rojizo también pueden encontrarse. Como parte del proceso se practicaron incisiones en hombros, muñecas, abdomen e ingles, las que luego fueron suturadas usando hilos de cabello humano o hebras de totora. Esto contrasta con las momias negras en las cuales ni incisiones ni suturas han sido observadas. En general, el tratamiento de la cabeza de las momias rojas fue más complejo que el de las negras. Este subtipo de momias ha sido hallado en Arica, Camarones, Punta Pichalo, Bajo Molle y Patillos. Aparece entre ellas la deformación craneana en forma anular. Cronológicamente se les ubica entre 2570 y 2090 a.C.

c) Momias en vendajes: el procedimiento parece una combinación de los usados para las negras y rojas. El cuerpo fue completamente descuerado y palos longitudinales fueron usados para reforzarlo. Después de esto, tiras de piel animal o piel humana, de alrededor de 2 $\mathrm{cm}$ de ancho, fueron usadas para envolver el cuerpo. La cabeza y cara fueron tratadas como en las momias rojas y los cuerpos pintados de rojo. Este subtipo se documenta para tres infantes y un adulto que sólo tiene vendadas las piernas. Se piensa que ellas fueron contemporáneas con las rojas.

d) Momias cubiertas de barro: los cuerpos eran ahumados y luego cubiertos con una mezcla de arena, arcilla y un ligamento proteico. Se les reconoce dos variantes: una con evisceración y otra sin ella. En el caso de las evisceradas, las cavidades eran rellenas con cenizas. Fueron preparadas en el mismo lugar donde fueron enterradas quedando adheridas al piso de la fosa. Todas se registran para Arica y, se supone que las sin evisceración son más tardías.

Guillén (1997) encuentra dos momias en el sitio Morro 1-5, que no encajan en las categorías propuestas por Allison y colaboradores (1984) y propone otro tipo, el que se caracterizaría por que la evisceración se realizó con cortes en la parte posterior del cuerpo; la reconstrucción se hizo con una densa capa de ocre y se colocó masas de arcilla externamente en sitios como debajo de las costillas. Según la investigadora, se trataría de una 
variante poco popular o de una simplificación del proceso en las etapas finales de la práctica de la momificación artificial.

\section{Antecedentes sobre las Colecciones}

El arqueólogo alemán Max Uhle, a principios del siglo XX habría excavado numerosos enterratorios "en la falda Norte del Morro de Arica" y una cantidad no precisada en "pampa de Chinchorro", a lo que hay que sumar numerosos ejemplares comprados. Estos materiales fueron los que le permitieron definir su período de los "Aborígenes de Arica" y dar a conocer lo que hasta ahora se conoce como "Momias Chinchorro". En su publicación de 1922 el investigador hace referencia a 11 momias completas y a un busto. Esta colección, o parte de ella, fue depositada originalmente en el Museo Histórico Nacional de Santiago, desde donde, en 1969, pasó al Museo Nacional de Historia Natural. Por otra parte, una pequeña momia que se encuentra en el Museo de la Universidad de Tarapacá, Arica (según registro del Museo de Azapa) y otras cuatro, en el Museo de Historia Natural de Valparaíso (Vera 1981), se piensa que pueden corresponder a las recolectadas por este arqueólogo. En el Museo Nacional de Historia Natural se analizaron 14 cuerpos momificados que se encuentran fragmentarios o casi completos; además, un tronco, cuatro porciones disgregadas de sus cuerpos y restos de un mamífero. En el Museo de Arica, se analizó la momia que allí se encuentra depositada y que correspondería a la colección Uhle $^{2}$.

Por su parte, Ancker Nielsen fue un ciudadano danés que se estableció en la ciudad de Iquique entre los años 1920 y 1925, donde adquirió una farmacia y, finalmente, llegó a ser Vicecónsul de Dinamarca en ese puerto. Desde su llegada a la localidad se interesó en la recolección de objetos arqueológicos y de momias, llegando, con el tiempo, a formar una importante colección. A su muerte, dicha colección iba a ser enviada al Museo Real de Copenhague, pero oportunas gestiones en la Municipalidad de Iquique impidieron que esto sucediera; finalmente, fue depositada en el Museo local (Munizaga y Martínez 1961). Nielsen habría excavado dos conjuntos contiguos de tumbas del Complejo Chinchorro en Patillos (costa sur de Iquique), con un total de 13 cuerpos (Núñez 1969), de los cuales nos fue posible analizar seis en el Museo Regional de Iquique.

Los estudios que, sobre las referidas colecciones se han llevado a cabo durante los ochenta y cincuenta años, respectivamente, desde que fueron exhumadas, han sido pocos. Mientras que Uhle publicó sus estudios y descripciones sucintas y parciales de sus colecciones (Uhle 1917, 1919, 1922), Nielsen sólo satisfizo su afán coleccionista y no generó ninguna publicación. Bittmann y Munizaga (1979) publicaron sus apreciaciones sobre un posible arco, que se encontraba en el interior de la momia $\mathrm{N}^{\circ} 11043$ de la colección Max Uhle. Munizaga y Martínez (1961) se ocuparon de la colección Nielsen, para la cual, sin entrar a detallar los especímenes, hacen un breve y general análisis, tratando de asimilar las momias a la tipología de Uhle. Por último, tanto Olmos y Sanhueza (1984) como Moragas (1995), dentro del contexto de sitios de la costa de Iquique y refiriéndose específicamente al sitio Patillos, sintetizan las características de la colección.

Como una forma de analizar y documentar dichos ejemplares surgió la idea de describir y reconstruir gráficamente, a escala, y con la mayor rigurosidad posible cada uno de ellos (Figuras 1 a 5). La acción erosiva durante el tiempo que estos cuerpos estuvieron bajo tierra, así como los factores ambientales operantes durante las décadas que ellos han permanecido en depósito en los museos, hacen que su estado de preservación sea precario. El estado de fragmentación en que se encuentran los cuerpos ha facilitado el análisis, al proporcionar condiciones de disección natural para la observación interna de la estructura y manufactura de los especímenes, sin necesidad de efectuar ninguna intervención sobre ellos. Las fracturas, desarticulaciones, desprendimientos de capas y pérdidas de porciones, han dejado expuestos atributos de la morfología interna. Por el contrario, la ausencia de partes de los cuerpos, el buen estado de algunas porciones o la compactación de otras, en algunos casos, fueron limitantes para poder disponer de más antecedentes analíticos al respecto. Aquellos restos muy fragmentarios o confusos no fueron considerados en el presente artículo ${ }^{3}$.

Con el fin de poder tener un referente cronológico de la colección Uhle, se obtuvo una muestra del relleno del cráneo del ejemplar $\mathrm{N}^{\mathrm{o}} 11052$, la que dio fecha de $3690 \pm 60$ a.p. (Beta-113382). 


\section{Colección Max Uhle del Museo Nacional de Historia Natural}

\section{Ejemplar 11037}

Extremidad superior y parte de una extremidad inferior de un adulto.

Extremidad superior: todos los huesos in situ y el tejido muscular adherido a ellos; un palo cilíndrico, semiaguzado en el extremo proximal y quebrado en el distal, recorre todo el miembro exteriormente hasta la muñeca; el miembro y el madero están envueltos con lo que parece ser un cuero con la lana hacia el interior; por encima del cuero y a mitad del antebrazo hay una amarra de varias vueltas. Finalmente se observa una faja textil, de un ancho mínimo (mensurable) de cuatro centímetros, a manera de vendaje, que se conserva desde el hombro hasta la mitad del antebrazo. Sobre el textil, hay vestigios de una cubierta resinosa. La mano, aunque desarticulada, pertenece al mismo brazo; se ve un vellón de lana en la cavidad palmar y cuero (que conserva su lana) envolviendo la mano, lo que hace pensar en continuidad del envoltorio del brazo. Finalmente fue atada con amarras espaciadas de lienza gruesa.

Extremidad inferior: tibia y peroné en posición anatómica con tejido muscular seco; no se observa mayor preparación; toda la pieza recubierta con emplasto de barro y arena. Bajo el barro se ve una capa de plumas. El pie se encuentra desarticulado.

\section{Ejemplar 11040}

Cuerpo de párvulo bastante completo, aun cuando sus piernas se encuentran desprendidas del cuerpo (mide aproximadamente $80 \mathrm{~cm}$ ) (Figura 1a y b).

Cabeza: la cabeza y la cara parecen cubiertas por un cuero muy delgado a manera de capuchón. Sobre el capuchón se ha enrollado un moderado turbante de cordelillo y, sobre todo ello, se observa vestigios de un emplasto resinoso. No hay evidencias de mascarilla, pero el cuero sobre la cara parece que hubiera tenido algún tipo de decoración en blanco y negro. El extremo aguzado de un trozo de palo cilíndrico penetra entre los filamentos del turbante, quedando el otro extremo a la altura del pecho.

Tronco y extremidades: el cuello, el tronco y las extremidades llevan un embarrilado continuo, aplicado directamente sobre la piel. El torso y los brazos aparecen cubiertos por una piel de ave. La mano se ve envuelta como por una funda de cuero, dejando libre los extremos de los dedos. Lleva una breve faja de lienza más gruesa que la lienza del embarrilado corporal.

El fardo ha sido amarrado con cordeles y, finalmente, envuelto en estera de ramas de totora enhebradas. Sobre la parte central del pecho tiene adherido un pequeño cesto coiled.

\section{Ejemplar 11041}

Cuerpo de un mamífero carnívoro (posiblemente Lutra felina) bastante destruido. Se conserva la columna vertebral con tejido muscular adherido, dos huesos largos, fragmentos de hueso del cráneo, parte de la mandíbula y fragmentos de costillas. En la caja se encuentra un palo cilíndrico aguzado en un extremo y quebrado en el otro (51 $\mathrm{cm}$ ), el que podría corresponder a un palo-eje. No hay evidencias de preparación compleja.

\section{Ejemplar 11043}

Cuerpo adulto sin cráneo con casi todo el esqueleto expuesto; desarticulado parcialmente, en especial las extremidades (136 cm desde la parte superior del cuello hasta los tobillos). En la misma caja hay un cráneo que no corresponde al cuerpo.

Cabeza: el cráneo que hay en la caja corresponde a un subadulto, en tanto el cuerpo es de adulto; las características de conservación (color, consistencia, etc.) de uno y otro son diferentes, por lo cual no pudieron estar enterrados juntos; las ramas de totora adheridas a la cara son más finas que las de la estera que cubre el cuerpo. Por todo ello la asociación de cabeza y cuerpo se habría producido con posterioridad a la exhumación.

Tronco: con tejido muscular seco adherido a los huesos, sin evidencias de preparación complicada. Hay fragmentos de totora en los resquicios del cuerpo, los que corresponden a la desintegración de la estera que lo envolvía y no al relleno de la momia.

Extremidades: en las extremidades inferiores se ve que conserva desecada toda su materia orgánica (músculos y piel); sobre ello, se observan porciones de un emplasto arenoso con inclusiones de la estera que envolvía el cuerpo. 


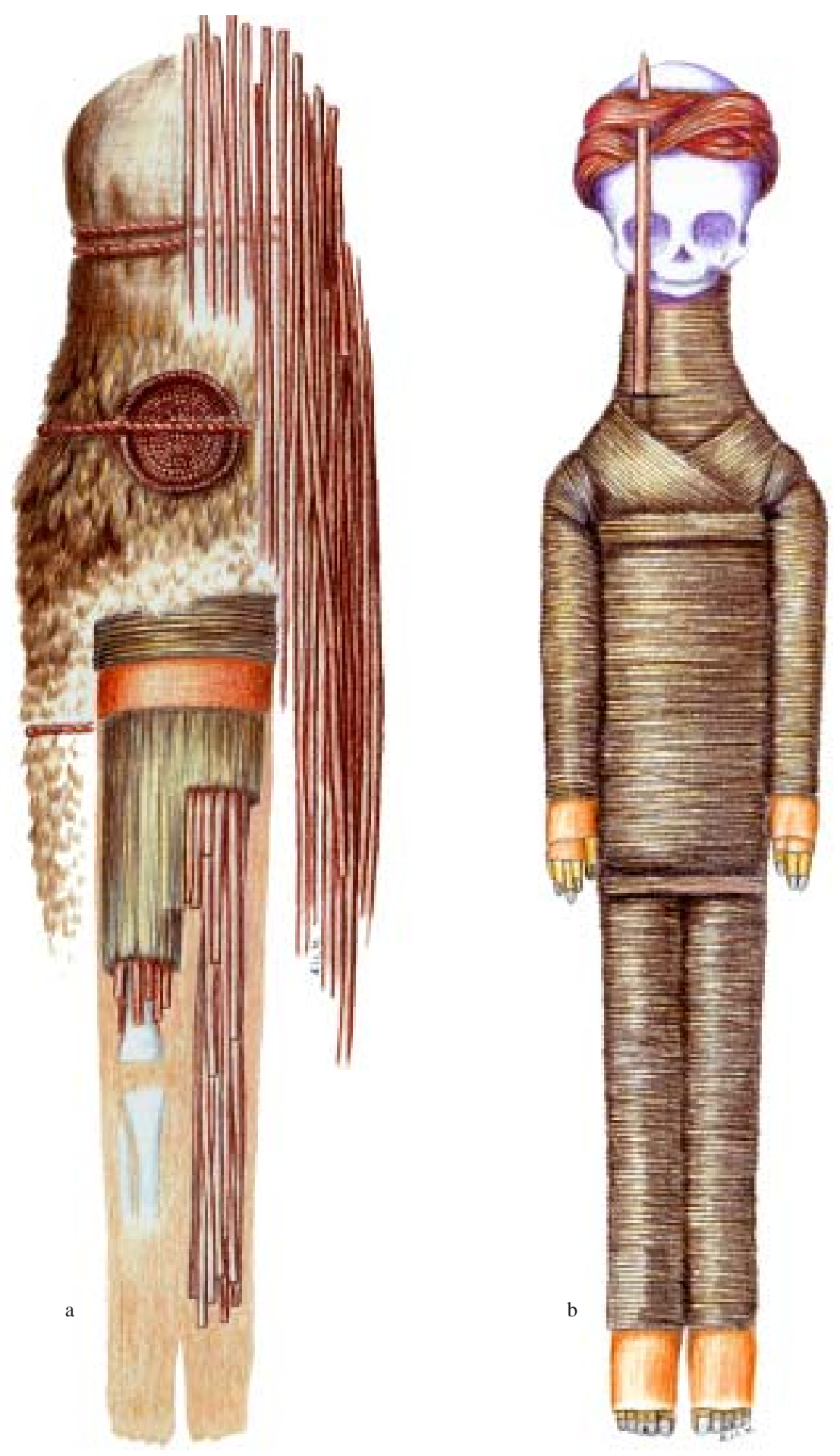

Figura 1. Reconstrucción gráfica del Ejemplar 11040: (a) disección esquemática mostrando en cortes las diferentes capas que constituyen la preparación mortuoria; (b) el ejemplar, sin las coberturas externas, destacando la disposición del embarrilado.

Line drawing of Specimen 11040: (a) schematic dissection showing the different layers that comprise the mortuary preparation; (b) the specimen, without exterior coverings, highlighting the layout of the wrapping. 
Maderos: en la caja hay dos palos largos, uno de los cuales corresponde al que fuera interpretado como arco por Bittmann y Munizaga (1979). Nos referiremos a ellos en las conclusiones.

\section{Ejemplar 11046}

Cuerpo de párvulo sin cabeza ni extremidades inferiores (aproximadamente $40 \mathrm{~cm}$ ).

Tronco: se nota claramente que el cuerpo no ha sido descarnado, sino que secado y sobre éste se ha efectuado el proceso de preparación. En la cara abdominal del tronco se acomodó longitudinalmente un manojo de totora, prolongándose para constituir el cuello; sobre éste, y también por la espalda, se acomodó una capa de paja, con las fibras también orientadas en forma longitudinal. Presenta un breve embarrilado (a modo de faja) a nivel de caderas y pelvis; el resto del tronco no está embarrilado.

Extremidades: no parece haber relleno en los brazos, los que tampoco están embarrilados.

Un emplasto de barro envuelve juntos el tronco y los brazos. Un envoltorio de piel de animal (con pelos hacia el exterior) se encuentra cubriendo tórax, abdomen y parte posterior del tronco. Nuevo emplasto de barro (parcial y somero) sobre la cubierta anterior. El cuerpo descansa sobre una estera de ramas gruesas de totora, unidas por amarras.

\section{Ejemplar 11050}

Cuerpo de niño (longitud estimada de $62 \mathrm{~cm}$ ) (Figuras 2a y b).

Cabeza: el cráneo, destruido, se encontraba relleno con material terroso con inclusiones laminares, heterogéneo. Hay trozos de cabellera postiza con costura sagital $\mathrm{y}$, sobre el pelo, una delgadísima capa de un material con aspecto de tiza; luego, un posible capuchón de cuero, sobre el cual se ubica el cintillo de cordelillos. Sobre toda esta composición, una cobertura resinosa. No se visualiza vestigios de máscara.

Tronco: con estructura de totora y cubierto con la piel, al parecer, en una sola pieza; en la base del cuello lleva una amarra circundante de pocas vueltas y, a la altura de la pelvis, un tupido faldellín de paja.

Extremidades: los brazos llevan una doble envoltura: una interna en vendaje y otra externa de una pieza (además del cuero que cubre todo). Las manos, como en otros casos, están envueltas por una funda de cuero, dejando la punta de los dedos al exterior. Las piernas presentan estructura de totora; en torno a ellas se puso una cobertura de barro resinoso delgado; a la altura de la pelvis y bajo la mencionada cobertura, una faja de lienza.

Finalmente, todo el cuerpo fue empaquetado con un cuero, amarrado con cordel vegetal y, por último, envuelto o depositado en una estera de ramas de totora enhebradas.

\section{Ejemplar 11051}

Este registro consta de dos piernas (hasta la rodilla, una con el pie in situ); una mano y un posible fragmento de mano. Todas estas porciones llevan un emplasto de barro directamente sobre el tejido muscular momificado.

\section{Ejemplar 11052}

Muy desarmada, sin cráneo; las piernas son lo que mejor se conserva, incluyendo los pies.

Cabeza: sólo queda la lana y el cuero que rellenaba el cráneo y el turbante de lienza.

Tronco: con estructura de ramas de totora dispuestas longitudinalmente; algunas van por dentro de la cavidad torácica y otras por encima de las costillas; a ello, se agregan manojos de paja encima de la totora. Sobre el pecho se observa piel de ave, dispuesta en capas. A la altura del pecho había numerosas semillas, posiblemente de pimiento (Schinus molle). Lleva faldellín de paja, el que llega hasta las rodillas.

Extremidades: sólo se conservan las piernas, en las cuales se observa algo como calcetas de piel amarradas bajo las rodillas; no se distinguen los dedos. En el muslo derecho se observa una costura que, más que para cerrar incisiones, parece hecha para ajustar la piel a la pierna; la izquierda no presenta este rasgo.

Finalmente, el cuerpo fue envuelto con una estera, cuyas varillas de totora fueron enhebradas con cuerdas de fibra vegetal.

Del relleno del cráneo de esta momia se obtuvo una fecha de $3690 \pm 60$ a.p.

\section{Ejemplar sin numeración (SN1)} $55 \mathrm{~cm}$ ).
Cuerpo de párvulo (longitud total se estima 

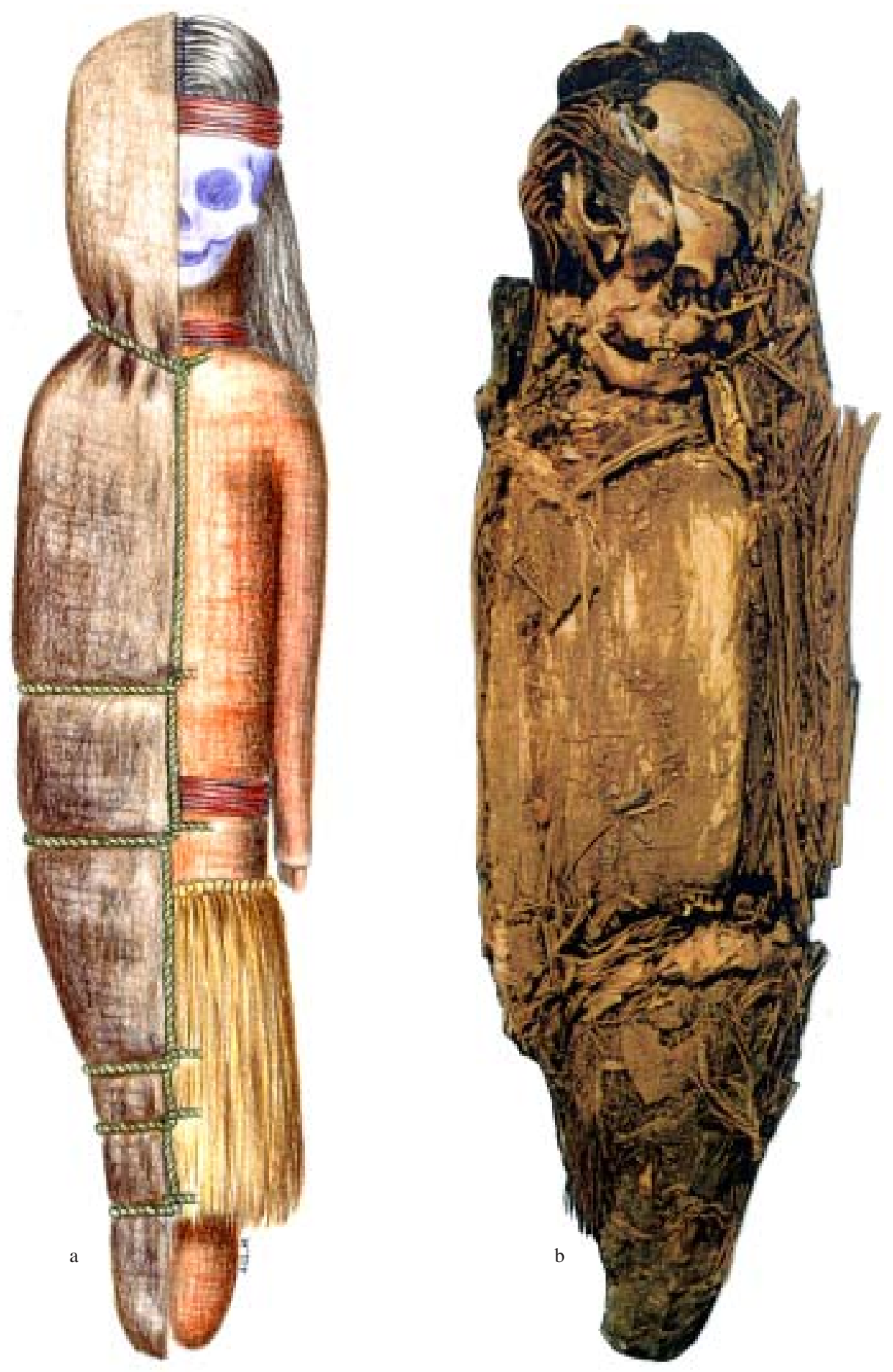

Figura 2. Ejemplar 11050: (a) reconstrucción gráfica; (b) fotografía directa del ejemplar. Specimen 11050: (a) graphic reconstruction; (b) photograph of the specimen. 
Cabeza: el cráneo está destruido; el turbante es regularmente abultado y confeccionado en lienza gruesa de color rojo; se conserva la cabellera postiza, en manojos, adherida al interior del turbante.

Tronco: la cavidad del tronco está rellena con material arcilloso amarillento. Un palo cilíndrico actúa como eje central del tronco, ubicándose longitudinalmente desde la pelvis hasta el cráneo. Tiene faja de lienza.

Extremidades: están cubiertas con arcilla rojiza, aplicada directamente sobre el tejido muscular deshidratado; además, sobre ella se agregó un emplasto de barro con arena. Sobrepuesta al emplasto de barro y arena se observa una piel de animal, especialmente en piernas y tórax. A la altura de la pelvis, sobre la arcilla y bajo el emplasto, se distingue un fajado de lienza. El emplasto de barro, como cubierta final, envuelve tronco y extremidades como un todo.

\section{Ejemplar sin numeración (SN2)}

Cuerpo de párvulo muy desarmado, del cual se conserva sólo el relleno correspondiente al tronco y cuello, además, parte del cráneo. Las características del tratamiento parecen idénticas a las de la Momia 11040, aunque no tiene palo-eje central.

Cabeza: el cráneo estuvo relleno con lana y el haz de totora que conforma el cuello se introducía en el cráneo; el turbante, de regular abultamiento, está confeccionado con lienza similar a la del cue1lo. La cabellera postiza presenta costura sagital y se encuentra embadurnada superficialmente con una capa delgada de una sustancia similar a tiza amarillenta.

Tronco: el núcleo está estructurado con totora y el relleno periférico es de paja; el cuello se encuentra embarrilado con lienza; las costillas y los omóplato se observan in situ, metidos entre la totora.

\section{Ejemplar sin numeración (SN4)}

Porción de una extremidad inferior de adulto (pierna y pie), con emplasto de barro directamente sobre el tejido muscular.

\section{Ejemplar sin numeración (SN6)}

Cuerpo de niño dispuesto en un fardo fusiforme de aproximadamente $65 \mathrm{~cm}$ de longitud (Figura $3 a)$.
Cabeza: la peluca presenta costura sagital; tanto la cabeza como la cara parecen estar cubiertas con un capuchón de cuero delgado sin pelaje. El turbante es ancho y confeccionado de cordelillo. Por la presencia de restos laminares adheridos irregularmente sobre la cabeza y el cuerpo, da la posibilidad de que hubo otro cuero cubriendo toda la cabeza y, tal vez, todo el cuerpo.

Tronco: el relleno del tronco corresponde a una estructura de ramas gruesas de totora cuyos extremos, amarrados en manojos, asoman a la altura del cuello. Se encuentra envuelto, por lo menos hasta el cuello, con piel de animal mostrando el pelaje hacia el exterior. A la altura de las piernas hay un mechón de pelo (al parecer humano), dispuesto longitudinalmente.

Extremidades: los brazos y las piernas se encuentran abultados con totora, la cual, en los primeros, se ubica especialmente entre los huesos y el tronco, y en las segundas, a los costados y en la parte dorsal.

\section{Ejemplar sin número (SN7)}

Cuerpo de párvulo que conserva el tronco y las piernas (sin los pies); faltan brazos y cabeza $(52 \mathrm{~cm})$

Tronco: desecado sin descarnar; el tórax está parcialmente relleno con un material de aspecto similar a la tiza; por el dorso se ven tres palos que corren por el exterior de la espalda. Un cuero de animal envuelve totalmente el cuerpo; el pelaje del cuero es amarillento y en la parte superior del cue1lo, rojizo.

Extremidades: las piernas, aparentemente, se encuentran sin relleno (compactas); cada una de ellas lleva un palo-eje central y está envuelta con vendajes de cuero animal con pelo, en cinta de 3 cm de ancho.

\section{Ejemplar sin numeración (SN8)}

Cuerpo de neonato totalmente desarmado.

Cabeza: el cráneo se encuentra relleno con vellones de lana y trozos de cueros, y los extremos de los atados de totora que conforman la estructura del tronco, penetran hasta tocar la calota; se conservan restos del cintillo de lienza y vestigios de peluca; esta última, se encuentra desarmada en forma de mechones amarrados y embarrados en un 

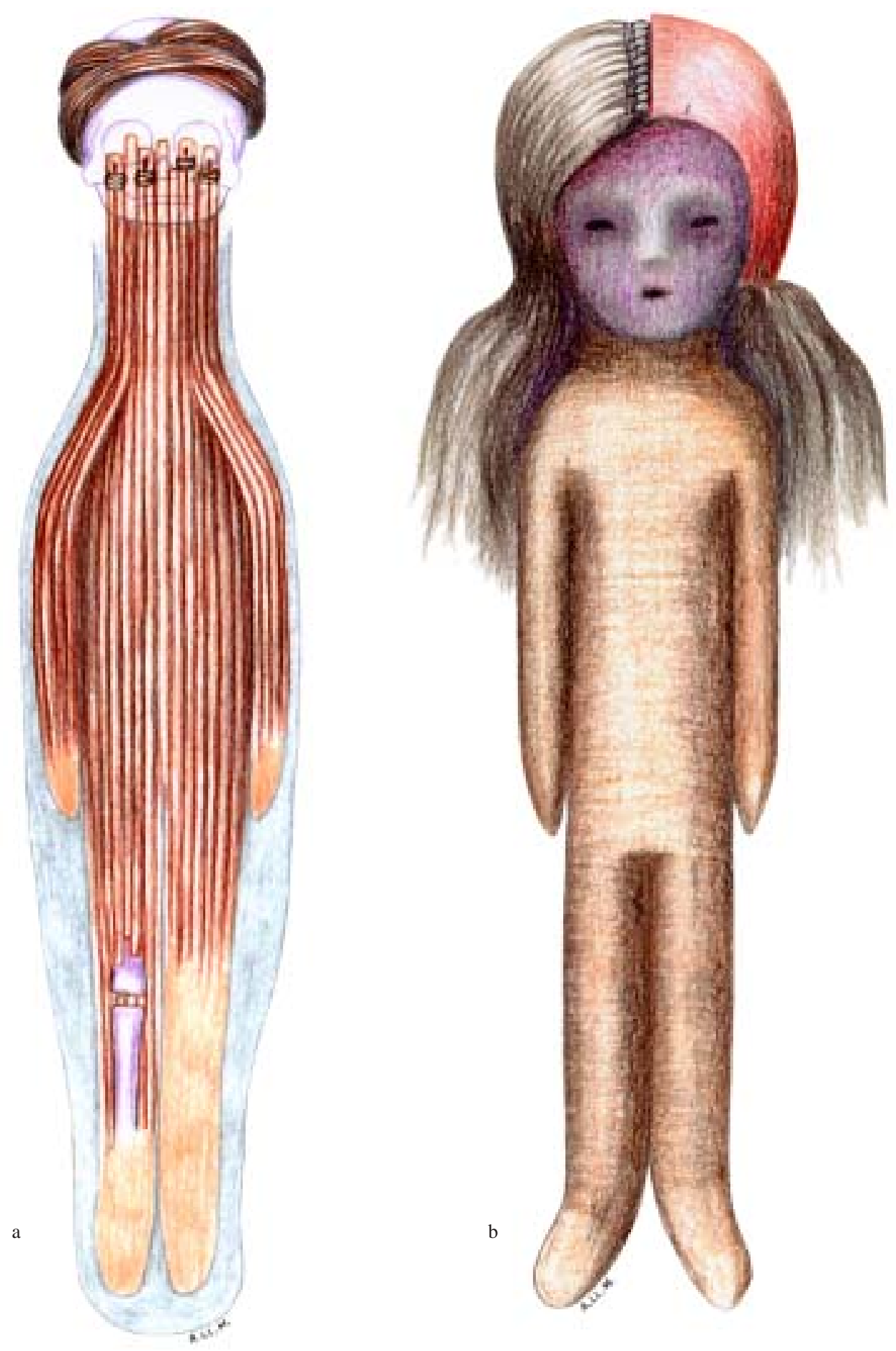

Figura 3. Ejemplar SN6 (a) exponiendo la estructura interior de ramas de totora; (b) ejemplar del Museo de Azapa en el que se destaca la mascarilla, la cabellera postiza con costura sagital y la capa dérmica. Specimen SN6 (a) showing the internal reed and twig structure; (b) Museo Arqueológico San Miguel de Azapa specimen showing mask, wig with sagittal seam and dermic layer. 
extremo, como que hubieran sido pegados independientemente en el enlucido del cráneo para armar la peluca.

Cuerpo: con estructura central de ramas de totora, entre las cuales se encuentran insertos los pequeños huesos de la criatura; en torno a este núcleo se ha dispuesto paja en atados, cuyos cabezales (ataduras) se ubican a la altura del cuello.

\section{Ejemplar sin numeración (SN9)}

Cuerpo de párvulo de aproximadamente tres meses; se encuentra desarmado y le falta una mano y la pierna derecha $(67 \mathrm{~cm})$ (Figura 4a).

Cabeza: la mascarilla, actualmente destruida, estuvo confeccionada en un empaste grueso de una sustancia similar a tiza de color crema, pintada superficialmente de negro; se aprecia que tuvo un modelado discoidal convexo sobre la cara; en el contorno de la máscara se encuentra el reborde de la peluca, característica que nominaremos como costura perimetral. Inmerso en la tiza por la superficie interior que contacta con el cráneo, se ven fragmentos de cordel grueso a manera de cintillo (circundando la cabeza a nivel de la coronilla), sólo dando dos vueltas a la cabeza. Sobre la peluca hay una cubierta superficial delgada, dura y negra, que se extiende a la máscara.

Tronco: se encuentra relleno con material arcilloso y, sobre la piel, una cobertura con un estuco delgado de color rojizo. Un palo cilíndrico va por la zona ventral, desde el pubis, pasando por la cara interna del esternón, hasta atravesar el paladar. Un palo corto a cada costado del tórax, junto a cada brazo. Tiene una ancha faja de lienza y un posible faldellín de piel de ave.

Extremidades: los brazos y las piernas son de color rojizo más oscuro que el tronco. Los huesos están cubiertos por una sustancia negra dura que puede corresponder a materia orgánica seca; sobre éstos, longitudinalmente, se disponen manojos de paja, con los cabezales a la altura de los hombros o del nacimiento de las piernas, contorneando los miembros para darle volumen; luego la piel del individuo y, por último, el estuco de barro. Las manos parecen estar envueltas por una funda de cuero, dejando los extremos de los dedos libres; algo similar acontece con los pies, pero sin dejar los dedos libres. Presenta amarras en las muñecas y en los tobillos.

\section{Ejemplar sin numeración (SN10)}

Cuerpo de adulto de aproximadamente 30 años (falta segmento abdominal por lo cual no se puede medir completo: $103 \mathrm{~cm}$ desde la cintura hasta los dedos de los pies).

Cabeza: cráneo con deformación circular oblicua. Sobre el rostro y la frente parece haber un engobe rojizo; no hay máscara. Tiene una peluca, cuya costura sagital se extiende desde la frente hasta la nuca; sobre la peluca se aprecia una delgada capa blanquizca que podría ser una especie de casquete de cuero muy delgado, que se mantiene como capa independiente sin mezclarse con el pelo. Turbante no abultado confeccionado con varias vueltas de lienza. Finalmente, un embarramiento general, que cubre el turbante, con restos adheridos de la estera de totora que envolvía todo el cuerpo.

Tronco y extremidades: secados en forma natural. La caja torácica mantiene su cavidad y órganos internos, por lo cual nunca fue manipulada. Lleva un faldellín de paja.

\section{Ejemplar sin numeración (SN11)}

Cuerpo de párvulo que se encuentra seccionado en tres partes y al que le faltan los pies (aproximadamente $59 \mathrm{~cm}$ ).

Cabeza: presenta la cara destruida; hay trozos de mascarilla de color oscuro; los ojos están representados por incisiones lineales horizontales circundadas por una incisión muy tenue. Lleva un turbante de cordelillo de lienza delgada; una piel de ave cubre todo y, sobre ella, una capa de arcilla similar a la del tronco.

Tronco: está relleno de material arcilloso. Un palo-eje va desde la cabeza hasta más abajo del pubis; el extremo superior de este palo se encuentra aguzado, en tanto que el inferior se aguza pero no termina en punta, la parte más ancha se ubica en la parte central del palo. Una faja de cordelillo rojizo envuelve caderas y pubis (más grueso que el del turbante). El tronco está cubierto por una capa de piel de ave, la que se continúa sobre brazos, cara y frente. Sobre las plumas hay una capa delgada de barro fino de color grisáceo. La capa de barro tiene en el vientre improntas de ramas transversales y paralelas que pueden corresponder a una estera.

Extremidades: los brazos llevan una cubierta de arcilla fina rojiza directamente sobre el tejido 

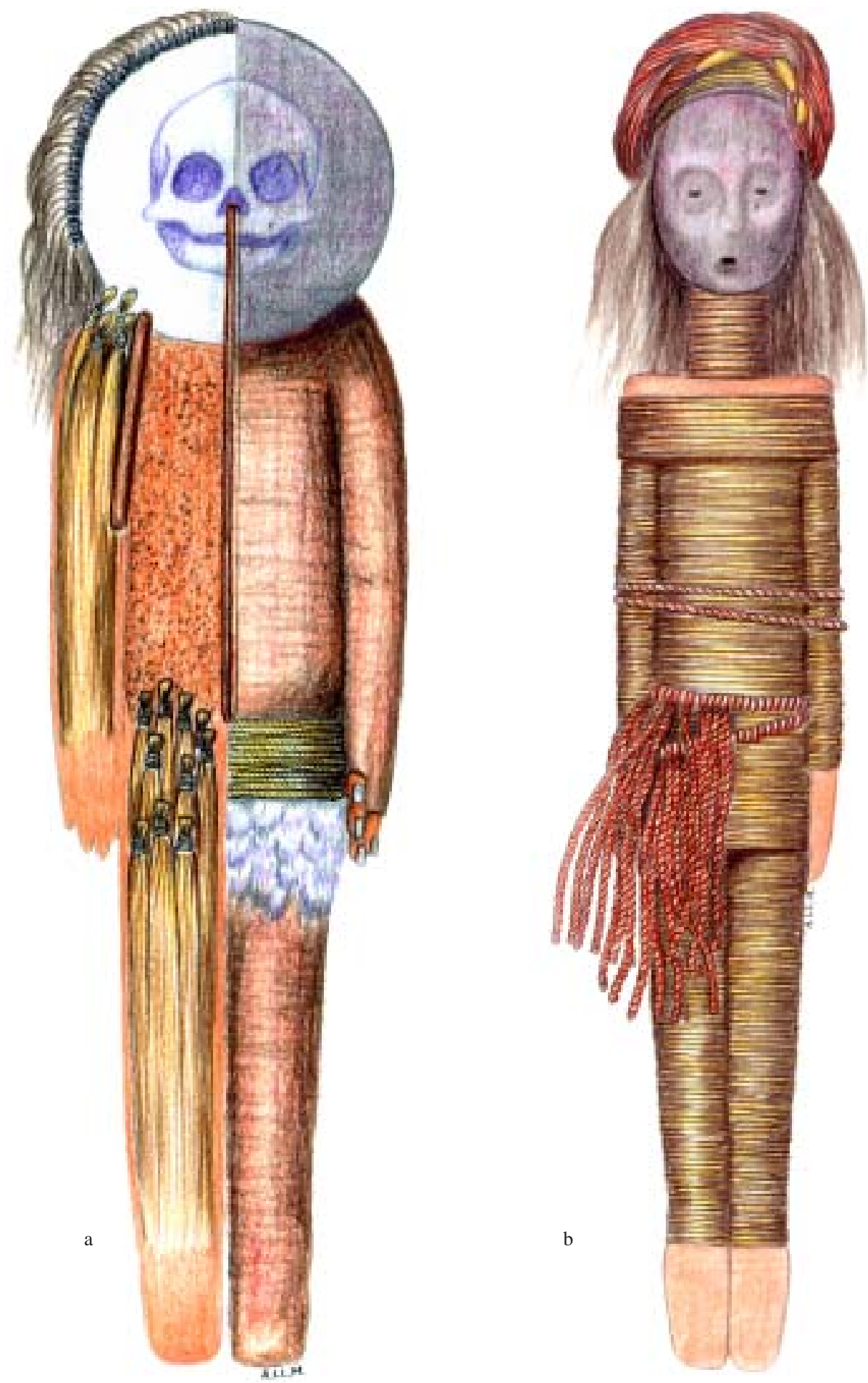

Figura 4. Ejemplar SN9 (a) el que muestra en su lado derecho los componentes interiores y en su lado izquierdo la apariencia externa; (b) reconstrucción gráfica del Ejemplar 2563 exponiendo su acicalamiento final.

Specimen $S N 9$ (a) the right side shows the inner elements while the left side shows the external appearance; $(b)$ graphic reconstruction of Specimen 2563 revealing its final appearance. 
muscular; se observa un embarrilado en la muñeca; sobre la arcilla hay piel de ave y, sobre ella, otra cubierta de arcilla grisácea que envuelve juntos brazos y tronco. Ambas piernas están cubiertas por barro grisáceo (no se puede observar al interior de ellas); presentan una amarra a la altura de las rodillas y otra a mitad de las antepiernas.

\section{Ejemplar sin numeración (SN12)}

Cuerpo con edad estimada en un año y medio. Muy deteriorado.

Cabeza: con el cráneo destruido y sin evidencias de mascarilla.

Tronco: tiene omóplatos, clavículas, costillas y vértebras in situ. La estructura de totora va por detrás y por encima del tronco, haciendo una especie de emparedado con el esqueleto; no parece haber relleno en la caja torácica. Sobre el tronco, y cubriendo los brazos, un cuero con lana. A la altura de las caderas, lleva una faja de la misma lienza mediana que el turbante.

Extremidades: brazos y piernas presentan estructura interna de totora; las ramas de totora van en forma continua desde el cuello hasta la mano haciendo una inflexión a la altura del hombro; la totora va por la parte dorsal del brazo. En el brazo parecen existir huinchas de vendaje.

Finalmente está envuelto en una estera enhebrada, similar a la de la Momia 11052. En la caja que contiene el cuerpo está la parte basal de un cesto coiled, de forma tronco-cónica invertida; la base mide $7 \mathrm{~cm}$. Si es que esta pieza corresponde al contexto, podría repetirse el caso de la Momia 11040.

Ejemplar del Museo Arqueológico San Miguel de Azapa

Cuerpo de niño muy completo y en buen estado de conservación (aproximadamente $60 \mathrm{~cm}$ ) (Figura $3 b)^{3}$.

Cabeza: conserva algunos fragmentos de mascarilla con manchas grises y rojizas. La boca está rellena con una masa de tierra verde. Lleva una peluca postiza con costura sagital y sobre ella un casco de arcilla rojiza.

Tronco: la estructura del cuerpo es de totora y externamente está cubierto con una delgada capa de arcilla con arena (café oscuro) y bajo ella, en algunos sectores, se observa un cuero con el pelaje hacia el interior.
Extremidades: Por la pierna derecha asoman dos palos hasta el pie (uno de ellos llega hasta la punta del pie). Los pies están perfectamente modelados en forma de escarpín. También se observa un palo en el brazo izquierdo que llega hasta la mano. El material verdoso que contiene en la boca está presente en parte de las piernas.

Esta momia podría corresponder a la que Uhle muestra en su publicación de 1922 (Lámina V, Figuras 1 y 1a); para la cual dice:

"Momia de una criatura de, más o menos, 2 años de edad. Todo el cuerpo está cosido en cuero, conservando su independencia las extremidades. En el revestimiento de barro que tiene la cara están indicados los ojos, la nariz y la boca; alrededor de ésta, se advierten líneas curvas, de color oscuro, quizás que parecen indicar una señal de tribu. La cabellera abundante, exagerada para un niño de edad tan tierna, es postiza" (Uhle 1922: 50).

La discrepancia radica en que la estatura estimada de este cuerpo no corresponde a los dos años de edad supuestos por Uhle, sino menos.

\section{Colección Ancker Nielsen del Museo Regional de Iquique}

\section{Ejemplar 2511}

Cuerpo de un niño mayor, con su tejido muscular deshidratado naturalmente, y con las cavidades rellenas con mezcla arcillosa.

Cabeza: tiene mascarilla gris con nariz muy bien modelada, con pequeños orificios nasales; los ojos aparecen insinuados por incisiones lineales horizontales; la porción bucal se presenta destruida; hay sectores, especialmente en los ojos, en que se advierte colorante verdoso. La máscara se asienta sobre una sustancia bituminosa. El pelo se encuentra in situ y con bitumen sobre éste. No hay evidencias de cintillo ni de turbante.

Tronco: un palo-eje va por el interior, junto a la columna vertebral hasta el cuello. Todo el cuerpo está cubierto por bitumen negro. Sobre este bitumen se encuentra adherida una capa de totora, cuyas ramas se disponen a lo largo del cuerpo, desde la cabeza a los pies.

\section{Ejemplar 2563}

Cuerpo de niño cuya longitud aproximada es de $110 \mathrm{~cm}$ (Figura 4b). 
Cabeza: lleva una máscara negra, apegada a los relieves de la cara y hacia los costados; tiene modelada la nariz. La máscara fue moldeada sobre el cráneo desecado o descarnado, ya que se visualiza el reborde de las órbitas. Tiene un abultado turbante el que parece ser doble: uno de lienza fina inmediatamente sobre el cráneo y otro, más grueso, sobre el anterior. En el más grueso, se encuentran embutidos tres instrumentos de hueso. Envolviendo el cráneo y la cara hay dos cueros o dos capas de un mismo cuero; uno, inferior, color café claro y otro superior, café oscuro; en el superior se distinguen algunas finas costuras. Parece tratarse de dos tipos de cueros diferentes, porque en varios sectores aparecen juntos pero sin continuidad entre ellos.

Tronco: embarrilado completamente (Figura 4b). Cuatro palos van a lo largo de la espalda entre el cuerpo y el embarrilado, y se introducen en el cráneo. La caja torácica está rellena con un rollo de estera que se proyecta y reemplaza al cuello. En el cuello, sobre la estera y los palos, hay una envoltura de cuero (sólo un palo va por fuera) y luego un embarrilado de cordel (más grueso que la lienza que embarrila el resto del cuerpo). El pecho está cubierto con un cuero delgado con pelo fino hacia el interior. Hay una amarra a la altura de los codos. Lleva un voluminoso faldellín de cordelillo con flecos de $20 \mathrm{~cm}$, dando al menos dos vueltas en torno a la cintura.

Extremidades: tanto los brazos como las piernas se encuentran embarriladas; las últimas están envueltas juntas por un cuero y amarradas con un cordel que las circunda cada cierto trecho. Faltan los pies. Sólo una mano queda expuesta y no se ve embarrilada.

Finalmente, el cuerpo se encuentra envuelto con dos esteras: una muy pegada al cuerpo (adherida a éste) y otra por encima. Tanto el cuerpo como el envoltorio tienen polvo oligisto.

\section{Ejemplar 2569}

Se trata de un "paquete" de forma ovoidal alargado de aproximadamente $68 \mathrm{~cm}$ de longitud, que contiene una cabeza de adulto y dos cuerpos de neonatos, junto con otros implementos (Figura 5a).

Cabeza: la cabeza pertenece a un adulto y se ubica en el extremo más ancho del paquete, tal como si fuera la cabeza real de un cuerpo com- pleto. Lleva una máscara rojiza que se ajusta al relieve de la cara por el frente y los costados; los ojos son hendiduras horizontales, en torno a las cuales se insinúan los contornos de las órbitas; la boca es una perforación sobre la cual se perfila el reborde de la maxila y se asoman dos dientes. Se observa pelo in situ. Tiene un voluminoso turbante confeccionado con manojos de lienza gruesa y delgada; en un sector tiene pigmento rojo. En el turbante se ha insertado tres instrumentos de hueso y uno de concha.

Cuerpos de neonatos: se ubican a la altura de lo que correspondería al pecho del imaginario cuerpo adulto, dispuestos longitudinalmente, uno sobre el otro, separados por un cuero. El inferior se infiere solamente por el cráneo y turbante que se asoma a la altura de lo que sería el falso cuello del adulto; por el costado derecho se observa un cilindro embarrilado que podría corresponder al brazo y, junto, pero más al interior del paquete, una masa de arcilla que podría ser el tronco de la pequeña momia. Del cuerpo superior queda claramente expuesta la cabeza con su pequeña mascarilla, muy similar a la del adulto, y su turbante con un penacho de plumas; próximo al mentón se ubica lo que pudiera ser un faldellín de cordelillos; un posible brazo pequeño embarrilado se encuentra bastante más desplazado de lo que sería su ubicación anatómica en relación a la cabeza; un embarrilado mayor se observa bajo el supuesto brazo, pudiendo corresponder al cuerpo. El cuerpo inferior parece ser algo más grande que el superior.

Implementos: en el interior del fardo se encuentran un cuchillo con hoja de piedra tallada y mango de madera, conchas de Oliva peruviana, cuentas de un collar, una aguja de madera y un instrumento de hueso; además, se encuentra, en el lado derecho, un tejido de trama y urdimbre que hacía parte de los envoltorios externos del fardo.

Todo este conjunto se encuentra envuelto con cuero, el que muestra algunas costuras finas, similares a las del cuero mencionado para el Ejemplar $2563 \mathrm{y}$, al igual que aquél, es doble: uno de mayor dureza y de color café oscuro, superpuesto a otro amarillento, delgado y flexible. El envoltorio de cuero está amarrado con cordel y, por último, un nuevo envoltorio de estera. Todo cubierto con polvo oligisto. 

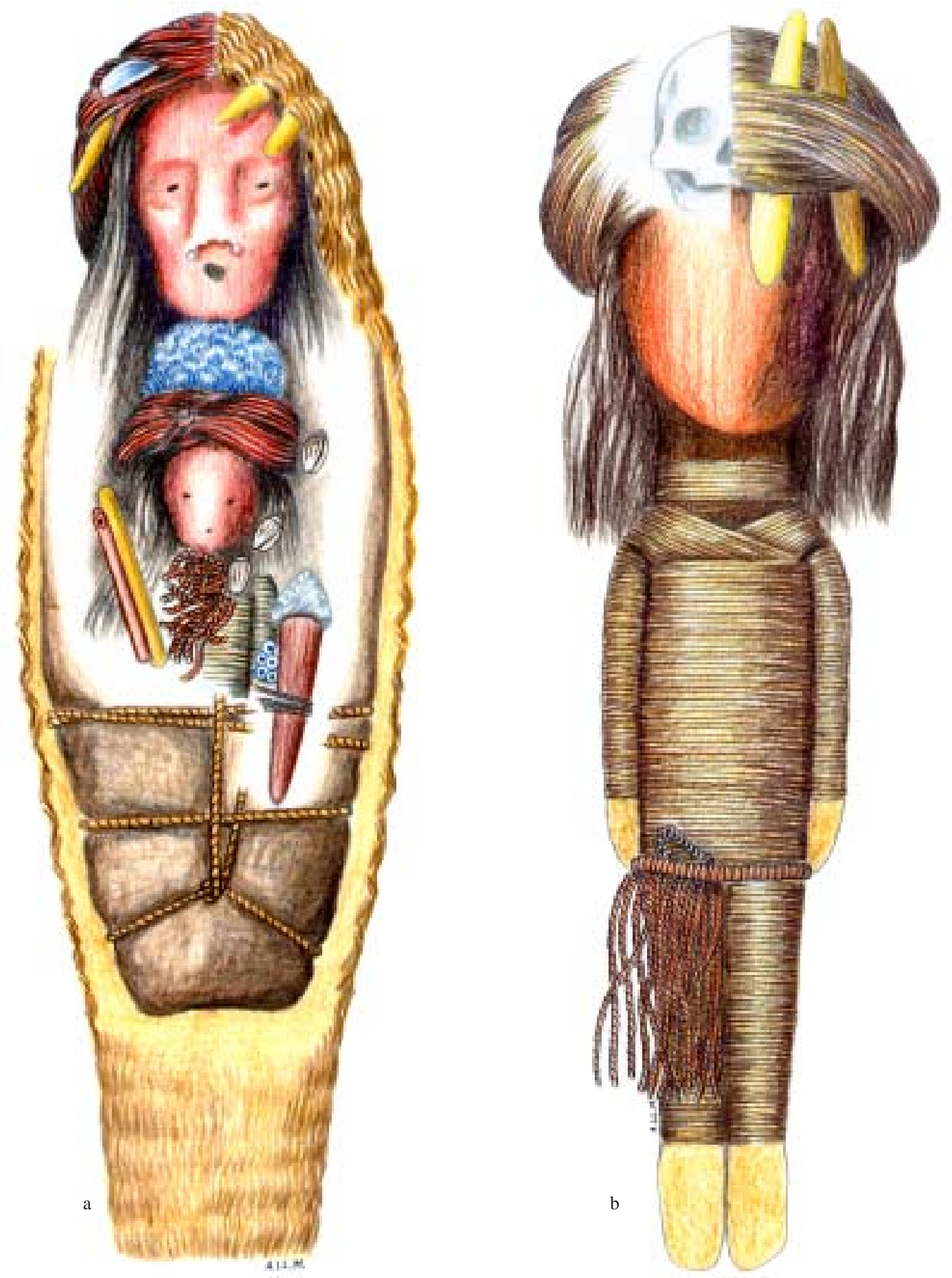

Figura 5. (a) Reconstrucción gráfica del "paquete funerario" 2569 destacando la cabeza de un adulto, una de las dos pequeñas momias y objetos dispuestos en el interior del paquete; (b) reconstrucción gráfica del Ejemplar SN5 destacándose el pequeño cráneo correspondiente al cuerpo, dentro de la desproporcionada gran cabeza falsa.

(a) graphic reconstruction of "funerary bundle" 2569, highlighting the head of an adult, one of two small mummies, and objects placed within the bundle; (b) graphic reconstruction of Specimen SN5 showing a small skull and a disproportionately large false head. 
Ejemplar 2571

Cuerpo de niño, completo y en buen estado de preservación. La cabeza se encuentra desprendida del cuerpo.

Cabeza: el cráneo no corresponde al cuerpo porque la estera, aun siendo del mismo tipo de la que cubre el cuerpo, es mucho más gruesa; además, el cráneo tiene restos de una sustancia bituminosa negra, no así el cuerpo.

Tronco: al parecer, se encuentra relleno con mezcla arcillosa; se alcanza a visualizar un hueso largo patinado que, a manera de eje, va por la parte exterior de la columna, viniendo de la parte inferior del tronco para terminar en el tórax. El tronco se encuentra totalmente embarrilado y, además, otro embarrilado va sobrepuesto de hombro a hombro, a modo de una ancha faja. En la base de lo que sería el cuello hay una especie de anillo de emplasto de barro con un cordel embutido, al parecer, para dar soporte al cráneo. En la juntura de este emplasto con el tórax existe evidencias de un collar: seis cuentas discoidales de concha (12 $\mathrm{mm}$ de diámetro) a las que se agrega fragmentos de hilo y, por lo menos, 22 cuentas más, las que se continúan con otro buen número por la espalda.

Extremidades: los brazos están totalmente embarrilados, a excepción de las manos. No es claro si las piernas tienen embarrilado completo; por lo menos, por un costado de la pierna derecha, se alcanza a ver un embarrilado que compromete todo el muslo hasta la rodilla. Un envoltorio de cuero cubre finalmente las piernas. Todo el cuerpo está envuelto con una estera y espolvoreado con oligisto.

\section{Ejemplar sin número (SN5)}

Cuerpo de niño con una longitud aproximada de $50 \mathrm{~cm}$. Llama la atención la desproporción de una gran cabeza con un cuerpo de párvulo (Figura $5 b$ ).

Cabeza: la cabeza visible es falsa. Se trata de material de relleno sustentado por un palo y un hueso largo que se proyectan desde el tronco; este soporte aparece recubierto con una máscara rojiza, gruesa, sin insinuaciones de rasgos; el lado derecho está relativamente bien terminado, en cambio, el izquierdo ha sido aplastado siguiendo el contorno cilíndrico del relleno. Tiene peluca y un abultado turbante; entre las lienzas de este último se insertan dos instrumentos (uno de madera y otro de hueso). En el interior del turbante hay un pequeño cráneo que correspondería al cuerpo del párvulo.

Tronco y extremidades: el tronco se muestra desecado y embarrilado; no parece tener relleno. El embarrilado envuelve el tronco y cada una de las extremidades en forma independiente. Entre el embarrilado y la espalda va un hueso largo que no pertenece al cuerpo y un palo pulido; el hueso se extiende desde el coxis hasta el vértice de la cabeza.

El cuerpo así preparado fue envuelto en cuero con su pelaje sin una disposición definida, al parecer, con la intención de dar más bulto al cuerpo; fue amarrado con cordeles, también, sin un patrón definido. Una sustancia bituminosa negra aparece embadurnando todo este paquete y comprometiendo también el turbante. Finalmente una estera de fibra vegetal, similar a la del Ejemplar 2571, recubre todo el conjunto.

\section{Comentarios y Conclusiones}

Por el diversificado estado de preservación e integridad de las momias analizadas, no todas las características han sido observables en igual grado en todas ellas. Un determinado rasgo está claramente expuesto en algunos ejemplares, en tanto que en otros puede no ser observable o ser confuso, por ausencia del sector que lo porta o porque su hermetismo no permite visualizarlo. Sin embargo y a pesar de las limitaciones, ha sido posible rescatar información valiosa en relación a los patrones de momificación en estas colecciones.

En la Colección Uhle queda en evidencia la existencia de dos patrones de momificación de acuerdo al material que se ha utilizado para estructurar la armazón de los cuerpos, ya sea éste, totora o material arcilloso. De acuerdo a esto, se contabilizan nueve ejemplares con armazón de totora (11040: Figura 1a y b, 11046, 11050: Figura 2a y b, 11052, SN2, SN6: Figura 3a, SN8, SN12 y ejemplar del Museo de Azapa: Figura 3b), dos ejemplares rellenos con arcilla (SN1 y SN11), uno mixto (SN9) y tres a los que no se ha podido determinar su estructura interna.

Las colecciones mayormente documentadas en la bibliografía arqueológica son las de Morro 1 (Allison et al. 1984; Standen 1997) y Morro 1-5 (Guillén 1997). En éstas, las momias de prepara- 
ción complicada se describen rellenas con arcilla, manganeso, lana de camélidos y totora, sin referencia alguna a cuerpos reemplazados por estructura de totora. Si bien es cierto que se documenta la reconstitución parcial de musculatura por totora en brazos y piernas, en este caso, se trata del reemplazo total del cuerpo -tronco y extremidades-, por un núcleo o maniquí cuidadosamente confeccionado con varillas de totora (Figuras 1a y $3 \mathrm{a}$ ). Las terminaciones más sofisticadas en la Colección Uhle están asociadas a estas momias de totora, ya que entre ellas se hacen presentes los casos de reposición de piel en vendajes y embarrilamiento exterior. De los nueve ejemplares de totora, sólo uno presenta mascarilla; para el resto, no hay evidencias de este aditamento; en su lugar, la cabeza completa parece haber estado recubierta por un capuchón de cuero delgado. La cabellera postiza, en todos estos casos, siempre lleva costura sagital.

En la publicación de Uhle (1922), aparte de los aspectos generales, pocas son las cosas que se pueden deducir de las descripciones que permitan relacionar los ejemplares de la colección con el texto de la publicación. En cuanto a referencias al relleno de totora y paja señala: "abultaban el tronco y las extremidades con totora, amarrándolos en seguida con cordeles y paja"(Uhle 1922:66); en otros párrafos, hace referencia puntual a la presencia de esta característica en algunos gráficos (Lámina III, Figura 1 y Lámina. III, Figura 3). Sólo para un caso (Lámina IV, Figura 4) hace alusión a embarrilado: "muestra muchas vueltas de pita delgada [en el cuello]"(Uhle 1922:49). En tanto que, en relación a la ausencia de mascarillas, afirma que no todas la tenían: "en otros casos, se contentaban con la pintura uniforme de la cara con blanco, amarillo, negro o rojo"(Uhle 1922:66).

Los ejemplares con relleno de arcilla se ajustarían a la descripción de las Momias Rojas definidas por Arriaza (1995). Al respecto, resulta interesante el espécimen SN9 (Figura 4a), por su carácter mixto (cuerpo relleno con arcilla y extremidades con armazón de totora y paja), pudiendo tratarse de un caso de transición entre los dos tipos.

En la colección Nielsen llama la atención que los ejemplares embarrilados no presentan estructura de totora, sino que se trata de cuerpos desecados o trabajados con arcilla. Estaríamos aquí, frente a un procedimiento diferente de taxidermia funeraria, el que nos plantea la existencia de varia- ciones regionales en los patrones de momificación. Asimismo, los especímenes iquiqueños presentan turbantes mucho más abultados que los de Arica, faldellines de flecos hilados, en lugar de fajas de lienza o de faldellines de paja, además de polvo de hierro oligisto y artefactos embutidos en los turbantes.

Los cuerpos cubiertos de barro sólo se hacen presentes en la Colección Uhle (11037, 11043, 11051, SN4 y SN10) y todos corresponden a ejemplares adultos. En un caso (SN10), se observa que se trata de un cuerpo no eviscerado; el resto, por tratarse sólo de porciones o porque las partes blandas no se han preservado, no es posible observar este atributo.

En relación a la disposición de dos cuerpos en un mismo fardo, caso del Ejemplar 2569, Bittmann (1982) señala que entre las momias encontradas por Sköttsberg en Arica había una momia "gemela" constituida por dos cuerpos de párvulos y, en la colección Nielsen, ella habría visto un fardo que contenía dos cuerpos de niños de corta edad, momificados en forma similar. Dado que no describe el ejemplar de la Colección Nielsen, es difícil saber si se trata del mismo al que hacemos alusión nosotros, pero, de cualquier manera, esto argumenta en favor de hechos ocurrentes, aunque no comunes.

No podemos soslayar el problema de la presencia de arco entre las poblaciones Chinchorro, sustentada por Uhle, ya que una de las momias analizada por nosotros corresponde a la misma que sirvió a Bittmann y Munizaga (1979) para refrendar la postura de Uhle. La observación del madero, asumido como arco por los mencionados autores, no nos permite apoyar esta idea, ya que lo que ellos consideran como "hombros recurvados", refiriéndose a la curvatura típica de los arcos, en este caso, presenta un nudo y justo allí una leve curvatura; consideramos que ésta es una conformación natural de la rama, ya que, además del nudo, hay un aplanamiento a favor de la curvatura, desde donde el palo disminuye notoriamente su espesor hacia el extremo. La sola presencia del nudo descalifica este palo como arco. Otro palo, con idénticas características y tamaño, pero sin curvatura, presenta en el extremo aguzado evidencias de haber sido expuesto al fuego y, hasta los $45 \mathrm{~cm}$, un pulimento por uso, lo que asignaría a estos artefactos otro tipo de función. Por otro lado, muchos palos 
de diferentes tamaños y con los extremos aguzados aparecen como palos-ejes al interior de las momias. Siempre queda la duda que si estos palos eran confeccionados ad hoc para reforzar los cuerpos o si tuvieron otra utilidad anteriormente, pero, definitivamente, debemos descartar su función como arcos.

Se podría afirmar que los ejemplares de estas colecciones corresponde a momentos tardíos del fenómeno Chinchorro. Aunque de la Colección Uhle tenemos sólo una fecha, la coherencia de ésta con las fechas de los cráneos pertenecientes a la misma colección ${ }^{4}$, respaldado por la homogeneidad de rasgos antropofísico (Costa et al. 2000a, 2000 b), hace pensar que lo medular de dicha colección provendría de un mismo sitio o, al menos, correspondería a un mismo momento, asignable al segundo milenio antes de la era cristiana.

La colección Nielsen puede ser considerada contemporánea o aún más tardía que la de Uhle, por la presencia de momias embarriladas, característica que definitivamente debemos circunscribirla como rasgo tardío en la momificación Chinchoro. En esta colección se agrega la presencia de turbantes abultados que, además, están actuando como portadores de objetos, rasgo que caracteriza la etapa Faldas del Morro, que es posterior a Chinchorro. Por consiguiente, la Colección Nielsen nos estaría mostrando el nexo entre estas dos etapas.

Las exiguas evidencias de tejidos, aunque bien desarrollados, en ambas colecciones, indicaría que estos chinchorros estaban en contacto con grupos que ya manejaban la textilería; por su parte, la presencia de cestos en la Colección Uhle podrían ser resultado de una situación parecida o, tal vez, piezas de una emergente actividad cestera que ellos habían comenzado a desarrollar.

Las fechas obtenidas para la Colección Uhle se sitúan en los finales de la fase que Arriaza (1995) nomina Chinchorro Transicional (2620 a 1720 a.C.). Este autor tipifica esta fase por la presencia de una amplia variedad de momias, caracterizadas por los estilos rojo y embarrado; sin embargo, no hace referencia a momias con maniquí de totora y embarriladas. La presencia de estos novedosos atributos y las características próximas a la fase $\mathrm{Fal}-$ das del Morro, abre nuevas expectativas en relación a los momentos finales del Complejo Chinchorro.
Estas espectaculares técnicas de preparación de cuerpos humanos fueron una de las más arcaicas manifestaciones ideológicas de los pescadores (Llagostera 1989). Serían los más antiguos rituales conocidos en América, a través de los cuales el hombre intenta un nexo con el mundo sobrenatural utilizando los propios cuerpos humanos. El hecho de que no todos los cuerpos fueron sometidos a taxidermia denota, no un patrón funerario generalizado a todos los miembros de la población, sino una intención diferente a la de la funebria propiamente tal, reservada sólo para individuos a los que se les ha asignado la específica función de ser mensajeros entre este mundo y el otro. El objetivo no es conservar el cuerpo de una persona determina$\mathrm{da}$, sino componer un ente con forma humana $\mathrm{y}$ con esencia humana. En el caso de los ejemplares con estructura de totora, ni siquiera se podría hablar de "momias" ya que no existe cuerpo momificado; de la persona, sólo se ha conservado el esqueleto y la piel.

El predominio de cuerpos infantiles frente a los adultos y la utilización de momias estatuillas (hechas en arcilla o hueso), a lo que ahora se agrega la preparación de complejos "paquetes", como los especímenes 2569 (Figura 5a) y SN5 (Figura $5 b$ ), hacen pensar que el objetivo no fue un culto propiamente a los muertos. Estas preparaciones, que podríamos conceptualizar como "composiciones votivas", deben haber formado parte de una concepción cúltica más amplia; tal vez, como símbolos o mensajes propiciatorios hacia las fuerzas naturales y sobrenaturales de la dimensión cósmica, siendo los propios difuntos los portadores de ellos. El afán de evitar la descomposición y procurar el acicalamiento de los portadores, indudablemente estaba relacionado con la perduración de la rogativa y de la adecuada presentación ante las entidades del más allá.

Agradecimientos: Se agradece a Eliana Durán, Jefe de la Sección Antropología del Museo Nacional de Historia Natural, Silvia Quevedo y a Cora Moragas, Directora del Museo Regional de Iquique, por facilitar el acceso a las respectivas colecciones. Este trabajo se desarrolló en el marco del Proyecto "El hombre arcaico costero: su biodiversidad y su bioadaptación” (Fondecyt 1960169), cuyo Investigador Responsable fue María Antonieta Costa. 


\section{Referencias Citadas}

Allison, M., G. Focacci, B. Arriaza, V. Standen, M. Rivera y J. Lowenstein

1984 Chinchorro momias de preparación complicada: métodos de momificación. Chungara 13:155-173.

Arriaza, B.T.

1995 Beyond Death: the Chinchorro mummies of ancient Chile. Smithsonian Institution Press, Washington.

Bittmann, B.

1982 Revisión del problema Chinchorro. Chungara 9:46-79.

Bittmann, B. y J. R. Munizaga

1979 El arco en América: evidencia temprana y directa de la Cultura Chinchorro (Norte de Chile). Indiana 5:229-250.

Costa, M.A., J. A. Cocilovo y S. Quevedo

2000a Patologías óseas, traumas y otros atributos en el grupo arcaico de Morro de Arica, Norte de Chile. Chungara 32 (1):79-83.

Costa, M. A., H. H. Varela, J. A. Cocilovo, S. Quevedo y S. G.

Valdano

2000b Perfil paleodemográfico de Morro de Arica, una población de pescadores arcaicos del norte de Chile. Boletín del Museo de Historia Natural 49: 215-235.

Guillén, S.E.

1997 Morro 1-5 (Arica): Momias y sociedades complejas del Arcaico de los Andes Centrales. Boletín de Arqueología PUCP 1: 65-78. Lima.

Llagostera, A.

1989 Caza y pesca marítima (9.000 a 1.000 a.C.). En Prehistoria, desde sus Orígenes hasta los Albores de la Conquista, editado por J. Hidalgo, V. Schiappacasse, H. Niemeyer, C. Aldunate e I. Solimano, pp. 57-79. Editorial Andrés Bello. Santiago.
Moragas, C.

1995 Desarrollo de las comunidades prehispánicas del litoral Iquique Desembocadura Río Loa. Actas del XIII Congreso Nacional de Arqueología Chilena. Hombre y Desierto 9 (1):65-80.

Munizaga, C. y S. Martínez

1961 La colección arqueológica Nielsen de Iquique. Revista Chilena de Historia y Geografía 129:232-246.

Nuñez, L.

1969 Sobre los complejos culturales Chinchorro y Faldas del Morro del Norte de Chile. Actas del IV Congreso Nacional de Arqueología Chilena. Rehue 2:111-142.

Olmos, O. y J. Sanhueza

1984 El precerámico en la costa sur de Iquique. Chungara 13:143-154.

Standen, V.G.

1997 Temprana complejidad funeraria de la Cultura Chinchorro (Norte de Chile). Latin American Antiquity 8:134156.

Uhle, $M$.

1917 Los aborígenes de Arica. Publicaciones del Museo de Etnología y Antropología de Chile 1 (4-5):151-176.

1919 La arqueología de Arica y Tacna. Boletín de la Sociedad Ecuatoriana de Estudios Históricos Americanos 3 (78):1-48.

1922 Fundamentos étnicos y arqueología de Arica y Tacna. (Segunda edición). Sociedad Ecuatoriana de Estudios Históricos. Quito.

Vera, J.

1981 Momias Chinchorro de preparación complicada del Museo de Historia Natural de Valparaíso: 3290 y 3060 A.C. Anales del Museo de Historia Natural de Valparaíso 14:5-17.

\section{Notas}

1 Usamos el término "lienza" para referirnos a un tipo de cordelería fina muy homogénea y apretada, del mismo tipo del que aparece en ovillos con anzuelos de espinas de cactáceas, utilizados como sedal para pescar, y que forman parte de la colección Uhle.

2 Esta momia fue donada por el propio Uhle al Instituto Comercial de Arica, el que posteriormente pasó a formar parte del actual Liceo Politécnico. Por gestiones de Bernardo Arriaza se logró que esta pequeña momia pasara a la colección del Museo San Miguel de Azapa. La momia se encontraba en una pequeña vitrina que sirvió para su exhibi- ción. Incluía una tarjeta con una descripción del individuo, firmada por el propio Max Uhle (nota de los editores).

3 Para la referencia de los especímenes se ha respetado la numeración registrada por los respectivos museos y, en el caso de aquellos que no presentan registro, se les ha asignado la sigla SN (sin número), agregándoles un número provisorio.

4 Análisis radiocarbónicos de dos tocados del conjunto de cráneos, que hacen parte de la colección Uhle, dieron como resultados $3660 \pm 50$ a.p. y $3730 \pm 50$ a.p. (Beta-113381 y Beta-113380). 